\title{
Despertando para a Programação com a Criação de Jogos
}

\author{
Valéria Cristina Gomes Leal ${ }^{1}$, Marcos Augusto F. Borges ${ }^{1}$, Amanda Oliveira ${ }^{1}$ \\ ${ }^{1}$ Faculdade de Tecnologia - Universidade Estadual de Campinas (UNICAMP) \\ Limeira - SP - Brazil \\ vckawauchi@hotmail.com, marcosborges@ft.unicamp.br, \\ amanda_1010a@hotmail.com
}

\begin{abstract}
This article describes an experiment with students, in order to demystify that learn programming is difficult. To spark interest and attract students, the methodology used was to develop the project around the theme of creating games. As a working tool, we used the Scratch programming environment. The project was designed in the form of Mini Course. The results demonstrate that the basic programming concepts were introduced through play and easy to understand. The methodology applied and the results achieved are described in this work.
\end{abstract}

Resumo. Este artigo descreve uma experiência realizada com alunos, com o objetivo de desmitificar que aprender programação é difícil. Para despertar o interesse e atrair os alunos, a metodologia utilizada foi desenvolver o projeto em torno da temática de criação de jogos. Como ferramenta de trabalho, utilizou-se o ambiente de programação Scratch. O projeto foi elaborado em forma de minicurso. Os resultados demonstram que os conceitos básicos de programação foram introduzidos de forma lúdica e de fácil compreensão. A metodologia aplicada e os resultados alcançados são descritos no presente trabalho.

\section{Introdução}

Na última década surgiram movimentos para mudar a visão de que programação é uma atividade complexa. São movimentos patrocinados por grandes empresas e organizações, como a Code.org e Microsoft, que lançaram os sites \#Code (2013) e \#EuPossoProgramar (2014), respectivamente. Estes sites apresentam a programação como uma nova linguagem, que todos podem falar, e de forma simples e divertida, criar o que desejar usando a codificação. Os ambientes propostos por essas iniciativas são intuitivos e a programação é feita com a montagem de blocos geométricos. Os participantes são apresentados a desafios de lógica que devem resolver. Os desafios têm sons, movimentos e imagens, o que tornam as atividades mais motivadoras. Surgiram também ambientes de desenvolvimento que utilizam este mesmo tipo de interface, o Alice (1999), Scratch (2004) e AppInventor (2009) são alguns destes ambientes de programação.

O objetivo deste projeto foi propor uma abordagem para ensinar programação de forma simples e motivadora, com a finalidade de despertar o interesse de jovens e adultos pela programação, a ferramenta escolhida para a realização do projeto foi o ambiente Scratch (2004). O projeto foi elaborado em forma de minicurso e oferecido em dois eventos para públicos diferentes, na semana de Tecnologia em Foco da Faculdade de Tecnologia de Limeira para alunos dos cursos de graduação e pós-graduação e 
também no evento Scratch Day realizado na Faculdade de Tecnologia de Limeira, adaptado para alunos dos cursos Fundamental e Médio. O restante do artigo apresenta trabalhos relacionados (seção 2), os materiais e metodologia empregados (Seção 3), os resultados e conclusões (Seção 4).

\section{Trabalhos Relacionados}

No trabalho de (Mello et al. 2015) é apresentada uma metodologia para o ensino de conceitos relacionados ao desenvolvimento de jogos para alunos do ensino fundamental. Nesse estudo de caso foram introduzidos aos alunos conceitos de criação de jogos com a ferramenta GameMaker 8.1. Os alunos foram motivados a desenvolver jogos durante as aulas. Ainda no trabalho de (Mello et al. 2015) ele faz uma revisão sistemática da literatura para identificar trabalhos relacionados ao ensino de desenvolvimento de jogos. Alguns dos trabalhos encontrados se referem a estratégias para atrair alunos e principalmente garotas para a ciência da computação. Uma dessas estratégias é o uso de jogos como forma de introduzir o tema da tecnologia da informação. Segundo (Battaiola, Domingues, Feijó et al. 2001), o uso de jogos é útil para motivar as pessoas na aprendizagem de conceitos básicos da computação. Outros trabalhos relacionados tratam do uso de atividades de desenvolvimento de jogos no ensino médio, a fim de promover uma melhoria na base de programação dos alunos que irão ingressar nos cursos de ciência da computação. (Mello et al. 2015)

Os trabalhos relacionados demonstram que conceitos relacionados ao desenvolvimento de jogos para auxiliar na aprendizagem da computação já vêm sendo utilizado por outros pesquisadores com estratégias e objetivos diversos.

\section{Materiais e Metodologia}

O ambiente Scratch foi desenvolvido pelo grupo Lifelong Kindergarten no Media Lab do Instituto de Tecnologia de Massachusets, este ambiente possibilita o desenvolvimento de aplicativos que integram recursos de multimídia e o aprendizado no ambiente envolve criação, experimentação, compartilhamento e reflexão (Cunha 2011). Além do ambiente Scratch o projeto fez uso de materiais como tutoriais e vídeos sobre Scratch, disponibilizados no site da comunidade ScratchBrasil (2014).

O projeto teve a participação de integrantes do Laboratório de Informática, Aprendizado e Gestão (LIAG) da Faculdade de Tecnologia de Limeira, para organizar o laboratório de informática e atuar como monitores no minicurso. Uma aluna de pósgraduação em Computação do LIAG elaborou e liderou a aplicação do minicurso. $\mathrm{O}$ projeto tinha como metas: apresentar o básico da lógica de programação de forma lúdica com a temática jogos; poder ser adaptado para alunos de diversas áreas e faixa etárias; aproveitar materiais disponíveis na internet e usar o ambiente de programação Scratch.

A execução do projeto foi dividida em: plano de curso, aula e avaliação. No plano de curso foram propostas dinâmicas para a construção de três jogos, figura 1 . 


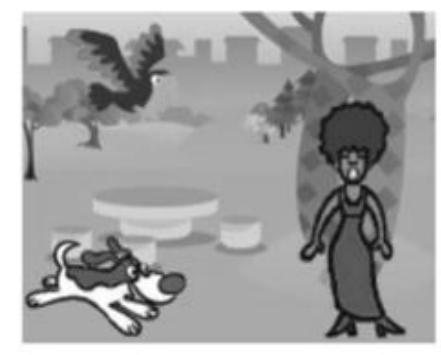

Siga o mouse

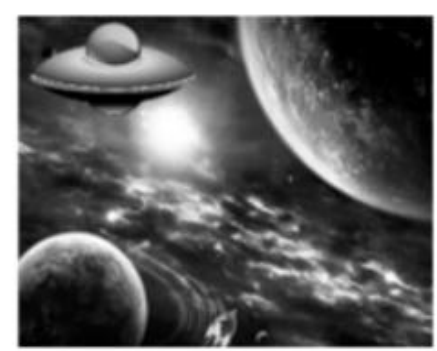

Batalha estelar

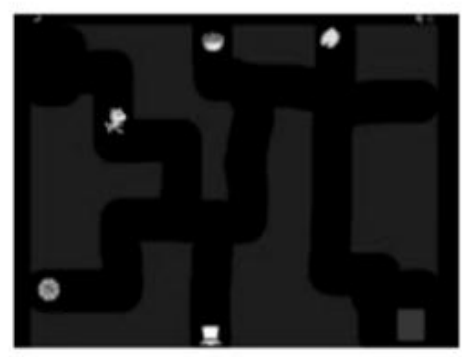

Labirinto

Figura 1. Criando Jogos com Scratch - Fonte: criação do autor

O primeiro jogo "Siga o Mouse", tem nível de dificuldade baixo: No processo de construção desse jogo, o aluno conhece o ambiente Scratch, trabalha com atores, cenários, sons e imagens. O aluno toma conhecimento dos blocos de programação, entendendo que são divididos por cores e funcionalidades. O segundo jogo "Labirinto", tem nível de dificuldade médio: Este jogo trabalha laços condicionais e a programação dos caminhos do labirinto é um bom exercício para testar condições. O jogo traz novas descobertas para os alunos que aprendem a usar sensores, mostrar e esconder atores, usar coordenadas na programação e a criar seu próprio palco no editor de imagem. $\mathrm{O}$ terceiro jogo "Batalha Estelar" tem nível de dificuldade alto, o aluno faz uma revisão dos conceitos anteriores e aprende conceitos novos, como variáveis, quando começa a contabilizar pontos no jogo. Durante a programação deste jogo, o aluno aprende a codificar enviando e recebendo mensagens. Cria uma fantasia para seu ator e explora laços de repetição e condição, usando os dois juntos.

A segunda fase do Projeto é a aula, onde o instrutor explica o que é um ambiente de programação e os alunos experimentam os jogos entendendo seu funcionamento. Os alunos acompanham o instrutor passo a passo na programação e conforme avançam na elaboração dos jogos, aprendem os conceitos básicos da programação na prática e testam o resultado dos seus erros e acertos.

O projeto elaborou três avaliações de validação para serem aplicadas com o minicurso. A primeira avaliação tem como principal objetivo avaliar o interesse do aluno sobre Computação e Programação; a segunda, uma adaptação da avaliação proposta por Bradley e Lang (1994), vai coletar dos alunos o grau de entendimento, motivação e interesse no minicurso e a terceira será responsável por extrair dos alunos alguma mudança sobre o interesse sobre Computação e Programação.

\section{Resultados Alcançados}

No primeiro evento participaram do minicurso alunos de graduação e pós-graduação com faixa etária entre 20 e 30 anos. Neste evento não houve avaliação com questionários, mas é possível passar a impressão do instrutor e dos voluntários sobre os alunos que participaram do minicurso: - No primeiro jogo, os alunos fizeram o proposto, e seguiram passo a passo o que o instrutor pediu, demonstraram grande motivação, com o processo de criar a animação, bastante simples. - No segundo jogo, os alunos passaram a entender melhor o ambiente e o jogo resultante tinha variações, conforme a imaginação e criatividade de cada um. Os alunos já buscaram explorar outras funcionalidades, colocando pontuação no jogo e níveis de dificuldades no labirinto. Neste ponto, começaram a explorar livremente o ambiente testando as possibilidades e as perguntas foram surgindo. - No terceiro jogo, com um nível de 
V Congresso Brasileiro de Informática na Educação (CBIE 2016)

Anais dos Workshops do V Congresso Brasileiro de Informática na Educação (CBIE 2016)

complexidade maior, os alunos demonstraram grande motivação para enfrentar o desafio proposto e programaram o jogo de batalha estelar sem grande dificuldade. Todos os alunos conseguiram terminar os três jogos. No final do minicurso, todos os alunos entenderam o funcionamento do ambiente Scratch e aprenderam os principais blocos de comandos. Um ponto percebido como negativo pelos alunos, foi a descoberta que o jogo desenvolvido no ambiente Scratch, não pode ser convertido em executável para ser jogado em celulares, tablets ou computadores que não tem o editor Scratch instalado ou online.

No segundo evento onde foi aplicado o minicurso para alunos do Ensino Fundamental e Médio o projeto elaborou três avaliações de validação para serem aplicadas com o minicurso e posterior analise dos resultados. Os participantes responderam três questionários em momentos diferentes do curso, o primeiro questionário foi respondido no momento da inscrição do curso, algumas das principais questões foram: - Tem interesse por programação? 28\% dos participantes responderam que sim e $72 \%$ que não. - As aulas de computação são interessantes? 60\% responderam que sim e $40 \%$ que não. No final do minicurso responderam um segundo questionário onde estas duas questões faziam parte: - Você tem interesse em continuar com aulas de programação Scratch? $88 \%$ responderam que sim e $12 \%$ responderam que não. - Você gostaria de fazer um curso de programação? 64\% responderam que sim e 36\% responderam que não. Ao final do curso responderam também um questionário avaliando o curso e o quanto aprenderam: - Diga o quanto gostou do curso: apenas $4 \%$ responderam não ter gostado muito. - Diga o quanto entendeu do curso: $12 \%$ responderam não ter compreendido bem os conceitos.

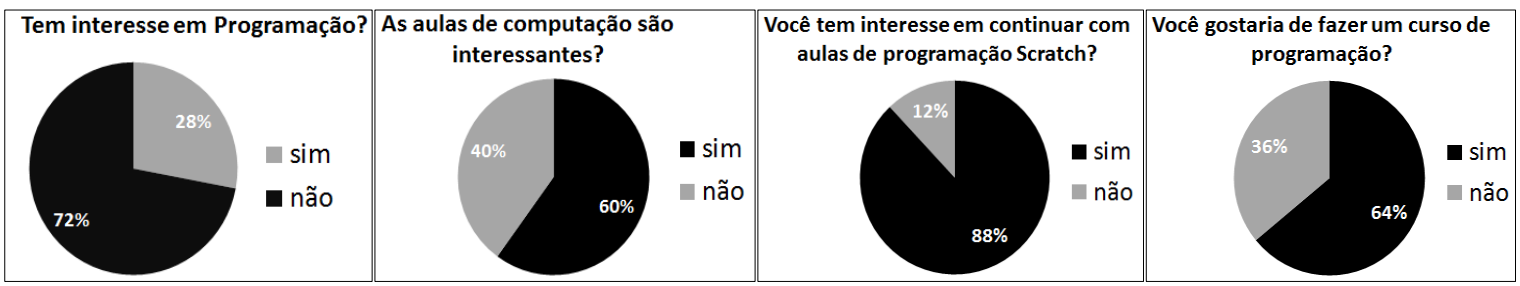

Figura 2. Gráficos da Pesquisa - Fonte: criação do autor

Mesmo o projeto sendo oferecido como um minicurso de poucas horas, observamos que a maioria dos alunos conseguiu programar os jogos sem grandes dificuldades. Os alunos mantiveram o interesse e a motivação em desenvolver os jogos durante todo o curso, inclusive nos níveis de maior dificuldade. Fizeram além do que foi proposto, criando variações interessantes para os jogos. Demonstraram interesse em saber mais sobre programação e alguns perguntaram por cursos futuros.

Diante dos resultados, o objetivo do projeto foi concluído de forma satisfatória: pode-se observar que foram introduzidos, conceitos básicos de programação de forma lúdica e de fácil compreensão, utilizando a estratégia observada e o Ambiente de Programação Scratch.

\section{Referências}

Alice (1999) Learn Programming, Carnegie Mellon University - http://www.alice.org

AppInventor (2009) MIT Instituto de Tecnologia de Massachusets http://appinventor.mit.edu 
V Congresso Brasileiro de Informática na Educação (CBIE 2016)

Anais dos Workshops do V Congresso Brasileiro de Informática na Educação (CBIE 2016)

Battaiola, A. L.; Domingues, R. G.; Feijó, B. et al. (2001). "Desenvolvimento de Jogos em Computadores e Celulares". RITA: Revista de Informática Teórica e Aplicada, 8(2): 7-46.

Bradley, M.M. e Lang, P.J. (1994). Measuring Emotion: The Self Assessment Manikin and the Semantic Differential, in: Journal of Behavioral Therapy and Experimental Psychiatry, 25, 49-59.

Cunha, R. R. M.; Scolaro, D. R.; Campos, J. L. "Do Scratch ao Arduino: uma proposta para o ensino introdutório de programação para cursos superiores de tecnologia." Em: COBENGE 2011.

Code.org (2013) Hadi Partovi - https://code.org/about

Eupossoprogramar (2014) Microsoft Brasil, Katia Gianone http://www.eupossoprogramar.com/

Mello, T. S. e Dantas, A. (2015). "GameMaking: Uma Metodologia para o Ensino de Informática para Alunos do Ensino Fundamental através da criação de Jogos Digitais”. Em Revista Brasileira de Informática na Educação, Volume 23, Número 1.

Scratch (2004) Lifelong Kindergarten no Media Lab do Instituto de Tecnologia de Massachusets - http://scratch.mit.edu

ScratchBrasil (2014) http://www.scratchbrasil.net.br/ 